\title{
Adaptation of the Narcissistic Personality Inventory among a Portuguese sample of incarcerated juvenile offenders
}

\author{
Pedro Pechorro ${ }^{a}$, Brittany Gentile ${ }^{b}$, James V. Ray ${ }^{c}$, Cristina Nunes ${ }^{d}$ and Rui \\ Abrunhosa Gonçalves ${ }^{a}$
}

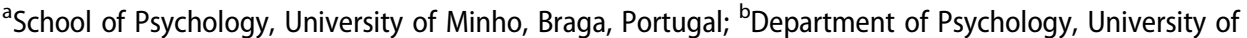
Georgia, Athens, GA, USA; 'Department of Criminal Justice, University of Texas at San Antonio, San Antonio,

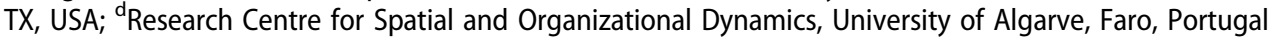

\begin{abstract}
The aim of the present study was to assess the psychometric properties of the Narcissistic Personality Inventory (NPI) and two of its short forms (NPI-16 and NPI-13) among a Portuguese sample of male incarcerated juvenile offenders $(N=221)$. Of these, only the NPI-13 short version demonstrated a good fit in terms of its factor structure. The NPI-13 also showed promising psychometric properties in terms of its internal consistency, convergent validity, discriminant validity, and criterion-related validity. Statistically significant associations were found with age of crime onset, crime seriousness, conduct disorder symptoms, alcohol abuse, and cannabis use. These findings justify the use of the NPI-13, especially its Entitlement/Exploitativeness dimension, among incarcerated male youths.
\end{abstract}

\section{ARTICLE HISTORY}

Received 4 April 2015

Accepted 10 February 2016

\section{KEYWORDS}

Assessment; Narcissistic

Personality Inventory; young offenders; psychometric properties

Narcissistic traits have been associated with juvenile delinquency, but the nature of this relationship and its importance within the judicial context has not been widely studied (Calhoun, Glaser, Stefurak, \& Bradshaw, 2000). Narcissistic traits, which are characterized by a grandiose, inflated sense of self and entitlement, preoccupation with success, and demands for admiration (see Morf \& Rhodewalt, 2001, for a review), may represent an important contribution to the study of delinquent and antisocial behaviors among adolescents (Chabrol, Van Leeuwen, Rodgers, \& Séjourné, 2009; Perez, Thoreson, Patton, \& Heppner, 1997). Although recognized as a personality disorder (Narcissistic Personality Disorder or NPD) in the DSM-5 (American Psychiatric Association, 2013) such severe manifestations are thought to be rare. Indeed, the construct is more typically understood as a personality trait (dimensional perspective) that varies normally in the population (Foster \& Campbell, 2007), albeit more prevalent among males (Foster, Campbell, \& Twenge, 2003; Robins \& Trzesniewski, 2005; Stinson et al., 2008) and younger age groups (Foster et al., 2003; Wilson \& Sibley, 2011). While there may be some short-term social benefits of narcissism (Campbell, Bush, Brunell, \& Shelton, 2005; Campbell \& Foster, 2007), over the long term it can have more negative consequences and is associated with a variety 
of negative interpersonal and behavioral outcomes (e.g. Bushman \& Baumeister, 1998; Campbell, Foster, \& Finkel, 2002; Nevicka, Ten Velden, De Hoogh, \& Van Vianen, 2011; Ryan, Weikel, \& Sprechini, 2008).

Given the inverse relationship between narcissism and age it should not be surprising that researchers are increasingly evaluating the narcissism construct and its implications for aggressive and maladaptive behavior among adolescent samples (Barry, Kerig, Stellwagen, \& Barry, 2011; Barry \& Kauten, 2014; Kauten, Barry, \& Leachman, 2013). As one of the most widely used measures of narcissism, we believe that it would beneficial to assess the psychometric properties of the Narcissistic Personality Inventory (NPI; Raskin \& Terry, 1988) in a sample of at-risk adolescents, specifically young males involved in the juvenile justice system. The present paper aims to assess the psychometric properties of the NPI and its short forms among male juvenile delinquents.

\section{Narcissistic Personality Inventory}

Raskin and Hall (1979) developed the NPI using the DSM-III criteria for NPD, later revising the measure to its current 40-item, forced-choice version (Raskin \& Terry, 1988). Despite using clinical criteria as the basis for the NPI items, the authors developed the instrument as a research tool intended to measure individual differences rather than as a diagnostic tool (Raskin \& Terry, 1988). The NPI measures narcissism as a personality trait, extreme manifestations of which may be indicative of pathological narcissism (Emmons, 1987), although there is no clinical cut-off score at which a person can be considered a 'narcissist' (Foster \& Campbell, 2007). As the NPI was originally based on a multifaceted conceptualization of narcissism, several early attempts were made by the authors of the measure (Raskin \& Terry, 1988) and others (Calhoun et al., 2000; Emmons, 1984, 1987) to define its factor structure in adolescent and adult samples, resulting in seven- (i.e. authority, self-sufficiency, superiority, exhibitionism, exploitativeness, vanity, and entitlement) and four-factor (i.e. leadership/authority (LA), superiority/arrogance, self-absorption/selfadmiration, and exploitativeness/entitlement) solutions, respectively. More recent research, however, has largely shown these factor structures to be unstable and found substantial evidence for a more parsimonious two- (e.g. leadership/authority and exhibitionism/entitlement; see Corry, Merritt, Mrug, \& Pamp, 2008) or three-factor solution (e.g. power, exhibitionism, and being special; see Kubarych, Deary, \& Austin, 2004).

In addition to uncertainty about the factor structure of the NPI, some have questioned its efficiency in research settings where time pressure and respondent fatigue are a concern (Ames, Rose, \& Anderson, 2006). In response, two short forms of the NPI have recently been developed: the NPI-16 (Ames, Cameron, \& Anderson, 2006) and NPI-13 (Gentile et al., 2013). Selection of items for the NPI-16 attempted to reflect the various facets of narcissism captured by the full NPI, such as authority, superiority, entitlement, and self-absorption. However, no a-priori factor structure was incorporated during its development and subsequent factor analyses have failed to find one with acceptable model fit (Gentile et al., 2013). Nonetheless, the NPI-16 has evidenced good validity and serves as a viable option under time constraints (Ames et al., 2006). In contrast, Gentile et al. (2013) developed the NPI-13 specifically to maintain the three-factor structure derived by Ackerman et al. (2011): LA, grandiose exhibitionism (GE), and Entitlement/ Exploitativeness (EE). The intended three-factor structure of the NPI-13 was supported 
by confirmatory factor analyses showing that it provided a better fit for the data than oneand two-factor models (Gentile et al., 2013).

\section{Narcissism and juvenile delinquency}

It has been suggested that narcissism is an important construct in understanding juvenile delinquency (Barry, Grafeman, Adler, \& Pickard, 2007). For instance, the maladaptive aspects of narcissism (e.g. exploitativeness and entitlement) may make youth more sensitive to personal threats and, in turn, individuals may be more likely to experience negative emotions such as anger which lead to the use of undesirable behaviors (e.g. aggression) in social situations (e.g. Baumeister, Smart, \& Boden, 1996). Additionally, youth who are highly narcissistic may engage in delinquent behaviors as a means to reestablish and maintain their perceived high social status among peers (Barry, Pickard, \& Ansel, 2009).

In line with these notions, research has consistently found an association between narcissism and antisocial behavior among youth and young adult samples (e.g. Barry et al., 2007; Chabrol et al., 2009; Miller et al., 2010). Additionally, research has found important associations between the NPI and external criteria known to be associated with juvenile offending. For instance, narcissism has long been tied to psychopathy (Lynam, 2011) and together with Machiavellianism, the three personality traits make up the 'Dark Triad', related by their common attributes of callousness, self-promotion, and aggressiveness (Paulhus \& Williams, 2002). Research confirms the relationship between narcissism, as measured by the NPI, and psychopathic traits among youth finding a positive association between the more maladaptive aspects of narcissism (e.g. Exhibitionism, Exploitativeness, and Entitlement) and measures of callous-unemotional traits (Barry, Frick, \& Killian, 2003; Feilhauer, Cima, \& Arntz, 2012). Several recent studies have found positive correlations between narcissism, as measured by the original NPI and NPI-16, and psychopathic, Machiavellian, and sadistic traits (NPI: Andershed, Gustafson, Kerr, \& Stattin, 2002; NPI16: Chabrol et al., 2009). Chabrol et al. (2009) also found evidence for positive relationships between narcissism, impulsivity, and risk-seeking. Similarly, research has found that narcissism and psychopathy exhibit similar relationships to components of impulsivity, specifically high approach and low avoidance motivation (Foster \& Trimm, 2008; Newman, MacCoon, Vaughn, \& Sadeh, 2005), as well as positive urgency and sensation-seeking (Miller et al., 2010).

Given the strong association between psychopathy and aggression (e.g. Porter \& Woodworth, 2006), it is also not surprising that research has likewise identified an association between maladaptive $f$ narcissism and measures of aggression (Ang \& Yusof, 2005; Barry et al., 2007; Washburn, McMahon, King, Reinecke, \& Silver, 2004). Among adults, narcissism has been linked to aggression following provocation and social rejection (Bushman \& Baumeister, 1998; Twenge \& Campbell, 2003), as well as a greater willingness to use physical or verbal aggression to resolve hypothetical disputes (Miller et al., 2011). Narcissism has also been linked to greater incidence of getting into physical fights (Miller et al., 2010), and lack of empathy (Watson, Grisham, Trotter, \& Biderman, 1984). Evidence for other externalizing behaviors has been less consistent with some research showing a positive relationship between narcissism and alcohol use (Luhtanen \& Crocker, 2005), stealing, and gambling (Miller et al., 2010) among young adults. 
In summary, the empirical evidence appears to suggest that narcissism may be an important feature underlying antisocial behavior among youth and that the NPI is a relevant measure among samples of antisocial youth. However, the extant research is limited in several ways. First, research examining the NPI has mainly focused on nondetained samples. A few studies used combined samples of community and detained youth to analyze the associations between narcissism and other variables (e.g. callousunemotional traits), making it impossible to determine how these relationships might manifest in a more homogenous sample of juvenile offenders. Additionally, few studies have examined the NPI cross-culturally, with the exception of Ang and Yusof (2005) who utilized a Japanese sample and Feilhauer et al. (2012) who utilized a Dutch sample. Thus, more research is needed to assess the psychometric properties of the NPI and its short versions among culturally distinct samples. Finally, to our knowledge only one study (i.e. Chabrol et al., 2009) has tested the utility of shorter versions of the NPI among samples of youth. This is an important line of research as juvenile offenders, particularly those detained in the justice system, may be most susceptible to the negative effects (e.g. fatigue) of lengthy surveys.

\section{Present study}

The aim of the present study is to address these limitations by attempting to assess the psychometric properties of the NPI, NPI-16, and NPI-13 among a sample of male youth who have been detained in the Portuguese juvenile justice system. To this end we first examined a number of proposed factor structures using confirmatory factor analysis. Then, contingent on the instrument demonstrating good model fit, we further examined its psychometric properties (e.g. internal consistency, construct validity, criterion-related validity). Given the instability of the NPI's factor structure, it was not expected that all adapted versions of the NPI would have good model fit. In assessing their psychometric properties, we expected our revised version(s) would demonstrate convergent validity with the related constructs of psychopathy and aggression, and divergent validity with the unrelated construct of social anxiety. We likewise expected our revised version(s) would demonstrate criterion-related validity with the behavioral constructs of age of crime onset, crime seriousness, conduct disorder, and risky behaviors (e.g. substance use and unprotected sex).

\section{Methods}

\section{Participants}

The sample was composed of inmates from eight nation-wide juvenile detention centers managed by the Portuguese Ministry of Justice. Two hundred and twenty-one male participants aged $13-20$-year-old $(M=16.75 ; S D=1.41)$ volunteered to participate in the study. The majority of participants were white Europeans (54.3\%), with the remainder of the sample comprised of ethnic minorities living in Portugal of predominantly African and South-American descent. Most of the participants came from an urban background (92.8\%). On average, participants reported their first criminal problems had begun at 11.33 years old $(S D=2.24)$ and were first detained before they were 16 years old 
$(M=15.46, S D=1.31)$. Participants were sentenced to an average of 21 months in detention $(M=20.67, S D=6.69)$, with the majority (87.6\%) convicted of violent crimes (e.g. homicide, robbery, assault, rape).

\section{Measures}

Narcissistic Personality Inventory (Raskin \& Terry, 1988)

The NPI is a 40 -item forced-choice measure. It is considered by far the most widely used measure of trait narcissism, and there is converging evidence that it contains two to three distinguishable factors (Ackerman et al., 2011; Corry et al., 2008; Kubarych et al., 2004). The NPI has two short forms: the NPI-16 (Ames, Rose, \& Anderson, 2006) and the three-factor NPI-13 (Gentile et al., 2013), with 16 items and 13 items, respectively. Although originally validated on adult samples, several previous studies have used the original NPI or adapted versions of this instrument with juvenile offenders (NPI-JO; Calhoun et al., 2000) and community samples of pre-adolescents and adolescents (Washburn et al., 2004).

\section{Antisocial process screening device - self-report (Caputo, Frick, \& Brodsky, 1999;} Frick \& Hare, 2001)

The antisocial process screening device - self-report (APSD-SR) is a multidimensional 20item measure of psychopathic traits in adolescents. It was modeled after the Psychopathy Checklist-Revised (Hare, 2003). Each item is scored on a 3-point ordinal scale $(0=N e v e r$, 1 = Sometimes, 2 =Often). The total score, as well as each subscale score, is obtained by adding the respective items with higher scores indicative of more psychopathic traits. In this study, the Portuguese version of the APSD-SR (Pechorro, Hidalgo, Nunes, \& Jiménez, in press; Pechorro, Maroco, Poiares, \& Vieira, 2013) was used. Internal consistency for the current study was as follows: APSD-SR total: $a=.81$, APSD-SR Callous-Unemotional dimension: $a=.68$, APSD-SR Impulsivity dimension: $a=.60$, and APSD-SR Narcissism dimension: $a=.74$.

\section{Youth psychopathic traits inventory (Andershed, Kerr, Stattin, \& Levander, 2002)}

The youth psychopathic traits inventory (YPI) is a 50-item self-report measure designed to assess the core personality traits of the psychopathic personality constellation in children aged 12-years-old and up. Each item is scored on an ordinal 4-point Likert scale (ranging from $1=$ Does not apply at all to $4=$ Applies very well). The YPI consists of 10 subscales (with 5 items each) designed in line with Cooke and Michie's (2001) three-dimensional conceptualization of the psychopathy construct (i.e. Grandiose-Manipulative, CallousUnemotional, and Impulsive-Irresponsible). Higher scores reflect an increased presence of psychopathic traits. The Portuguese validation of the YPI (Pechorro, Andershed, Ray, Maroco, \& Gonçalves, 2015) was used. The internal consistency for the current study, estimated by Cronbach's $a$, was as follows: YPI total: $a=.90$, YPI G-M: $a=.86$, YPI C-U dimension: $a=.70$, and YPI I-I dimension: $a=.79$.

\section{Reactive-proactive aggression questionnaire (Raine et al., 2006)}

The reactive-proactive aggression questionnaire (RPQ) is a self-report measure that assesses reactive and proactive aggression. The RPQ consists of 23 items (11 reactive and 12 proactive) rated on a 3 -point ordinal scale $(0=$ Never, $1=$ Sometimes, and $2=$ Often $)$, 
with higher scores indicative of higher levels of aggression. The measure produces reactive, proactive, and total aggression scores and is considered appropriate for use with late adolescent and young adult samples. The Portuguese validation of the RPQ (Pechorro, Ray, Raine, Maroco, \& Gonçalves, in press) was used. Internal consistency for the present study, estimated by Cronbach's $a$, was as follows: RPQ total: $a=.93$, RPQ Reactive: $a=.86$, and RPQ Proactive: $a=.91$.

\section{Social anxiety scale for adolescents (La Greca \& Lopez, 1998)}

The social anxiety scale for adolescents (SAS-A) is an 18-item self-report measure designed to assess subjective experience of social anxiety in adolescents. Each item is rated on a 5point scale (ranging from $0=$ Not at all, to $4=$ All the time). The measure contains three subscales: Fear of Negative Evaluation (FNE; 8 items), Social Avoidance and Distress - New subscale (SAD-New; 6 items), and Social Avoidance and Distress - General subscale (SAD-General; 4 items). The FNE subscale reflects fears, concerns, or worries regarding negative evaluations from peers. The SAD-New reflects social avoidance and distress with new social situations or unfamiliar peers. Lastly, the SAD-General reflects more generalized or pervasive social distress, discomfort, and inhibition. Scores are obtained by summing the items comprising each subscale. The Portuguese validation of the SAS-A (Pechorro, Ayala-Nunes, Nunes, Maroco, \& Gonçalves, in press; Pechorro, Silva, Maroco, \& Gonçalves, 2014) was used. Internal consistency for the present study, estimated by Cronbach's $a$, was: SAS-A total: $a=.91$; SAS-A FNE: $a=.91$; SAS-A SAD-New: $a=.89$; SASA SAD-General: $a=.75$.

\section{Child and adolescent taxon scale (Harris, Rice, \& Quinsey, 1994; Quinsey, Harris,} Rice, \& Cormier, 2006)

The child and adolescent taxon scale (CATS) is an actuarial rating scale that assesses childhood and adolescent antisocial and psychopathic characteristics. Harris et al. (1994) established eight childhood factors could identify members of the antisocial/psychopathic class including (a) elementary school maladjustment, (b) teen alcohol abuse, (c) childhood aggression, (d) childhood behavior problems, (e) parental alcohol problems, (f) suspended or expelled from school, $(\mathrm{g})$ separated from parents before age 16 , and $(\mathrm{h})$ arrested before age 16. The eight factors scored either 0 (No) or 1 (Yes), and summed to form a scale that ranges from 0 to 8 . Higher scores indicate more antisocial and psychopathic characteristics.

\section{Sellin-Wolfgang index of crime seriousness (Wolfgang et al., as cited in White et al., 1994)}

The index of crime seriousness (ICS) is a classification scheme for coding the seriousness of crimes based on official court reports. Scoring for the ICS is as follows: Level 0 - no delinquency, Level 1 - minor delinquency committed at home (e.g. stealing minor amounts of money from mother's purse), Level 2 - minor delinquency outside the home (e.g. shoplifting something worth less than 5 euros, vandalism and minor fraud), Level 3 - moderately serious delinquency (e.g. any theft over 5 euros, gang fighting, carrying weapons, and joyriding), Level 4 - serious delinquency (e.g. car theft, breaking and entering), and Level 5 at least two of each of the Level 4 behaviors. The ICS was used in the current study to index the seriousness of the each participant's offense. 
In addition to the measures listed above, each participant completed socio-demographic questions regarding their age, nationality, ethnicity, residential setting (rural vs. urban), education level, socioeconomic status, and parental marital status. They also completed questions regarding whether they had engaged in past drug abuse, alcohol abuse, or unprotected sex. Each participant was assessed for Conduct Disorder (CD; American Psychiatric Association, 2013) by the first and last authors of this article using the official DSM-5 diagnostic criteria.

\section{Procedures}

\section{Translation procedures}

Prior to conducting any analyses, the NPI was translated (NPI-JO; Calhoun et al., 2000), including the shorter versions (Ames et al., 2006; Gentile et al., 2013), using appropriate procedures (e.g. avoiding item bias or differential item functioning; Hambleton, Merenda, \& Spielberger, 2005). The initial translations from English into Portuguese were completed by the first and last authors of this article. Calhoun et al. (2000) simplification procedure that included some degree of rewording of the items was followed because some of them were difficult to understand. The translation was piloted tested on a small group of juveniles that were not included in the present analysis. This was done to make sure that all the items would be understood by the participants (i.e. that the wording of the items was consistent with the reading abilities of the adolescents).

The questionnaire was then independently back-translated into English by a native English speaker with considerable professional experience in translating psychologyrelated scientific texts. The original and the back-translated items were compared for non-equivalence of meaning, and discrepancies were revised until no semantic differences were detected between the English and Portuguese versions (i.e. the translated items had the same or very similar meanings compared to the original English items).

\section{Data collection procedures}

Authorization to assess the juvenile prisoners was obtained from the General Directorate of Reintegration and Prison Services - Ministry of Justice (Direção-Geral de Reinserção e Serviços Prisionais - Ministério da Justiça). The detainees, from the eight existing Portuguese Juvenile Detention Centers that admit male youths, were informed about the nature of the study and asked to voluntarily participate. The participation rate was approximately $92 \%$. Reasons for not participating in the study included: refusal to participate $(5 \%)$, inability to participate due to a lack of Portuguese fluency (2\%), and inability to participate due to security restrictions (1\%). All the measures used in this study were administered by means of individual face-to-face interviews to allow for more in-depth access to each participant and to assure a sense of privacy when gathering the data. It was stressed that there were no right or wrong answers and that for each item the participant should consider how he generally thinks or feels when responding. Some of the information (e.g. socio-demographic variables) was obtained from self-reports. Institutional files were used to complement the information obtained (e.g. prior criminal activity and detentions). 


\section{Data analyses}

The data were analyzed using SPSS v22 (IBM SPSS, 2013) and EQS 6.2 (Bentler \& Wu, 2008). The factor structure of the Portuguese language version of each NPI version was assessed using Confirmatory Factor Analysis (CFA) in EQS 6.2 (Bentler \& Wu, 2008; Byrne, 2006), with robust maximum likelihood (ML) estimation. Goodness of fit indices were calculated, including Satorra-Bentler chi-square/degrees of freedom, comparative fit index (CFI), incremental fit index (IFI), root mean square error of approximation (RMSEA), and Akaike Information Criterion (AIC). In terms of cut-off values, $x^{2}<5$ is considered acceptable, $x^{2} \leq 2$ is considered good, and $\chi^{2}=1$ is considered very good (Marôco, 2014; West, Taylor, \& Wu, 2012). Likewise, $C F I \geq .90$ and RMSEA $\leq .08$ indicate adequate fit, whereas $C F I \geq .95$ and RMSEA $\leq .06$ indicate good model fit (Byrne, 2006). For the incremental fit index (i.e. Bollen's IFI) values $>.90$ are regarded as acceptable. Lastly, lower AIC values indicate a better relative model fit among multiple nested or non-nested models (West et al., 2012).

The CFA was performed on the original scale items and only those with standardized loadings greater than .30 were retained. Modification indexes were examined to see if any modifications would significantly improve the measurement model, but none were used. Correlation matrixes with robust methodologies were used to conduct the CFAs as they provide more accurate estimates for categorical items (Byrne, 2006).

With regard to the psychometric analyses, Pearson correlations were used to analyze associations between scale variables, Spearman correlations were used to analyze associations between ordinal variables, and point-biserial correlations were used to analyze associations between nominal dichotomous variables and scale variables (Leech, Barrett, \& Morgan, 2015). In terms of internal consistency, results were considered good if the Kuder-Richardson (K-R) coefficient was above the minimum recommended value of .70 (Cortina, 1993), if the mean inter-item correlation was within the recommended range of .15-.50 (Clark \& Watson, 1995), and if the corrected item-total correlation was above the recommended value of .30 (Nunnally \& Bernstein, 1994).

\section{Results}

Our first step in examining the psychometric properties of the Portuguese version of the NPI and its two short forms was to attempt to replicate some of the proposed factor structures, particularly those proposed for adolescent samples. Table 1 shows the goodness of fit indexes for each of the tested models, specifically: one-factor model, seven-factor

Table 1. Goodness of fit indexes for the different ML models of the NPI.

\begin{tabular}{llllrr}
\hline NPI & S-Bx ${ }^{2} / \mathrm{df}$ & IFI & CFI & RMSEA & AIC \\
\hline 1-factor NPI & $11338.55 / 595$ & .75 & .75 & $.15(14-.15)$ & 2107.34 \\
7-factor NPI & $1374.23 / 539$ & .67 & .66 & $.08(.08-.09)$ & 296.33 \\
3-factor NPI & $1330.08 / 557$ & .69 & .69 & $.08(.07-.09)$ & 216.08 \\
1-factor short NPI-16 & $574.47 / 104$ & .75 & .75 & $.14(.13-.15)$ & 366.47 \\
1-factor short NPI-13 & $182.60 / 65$ & .93 & .93 & $.09(.08-.11)$ & 52.60 \\
3-factor short NPI-13 & $139.36 / 62$ & .96 & .96 & $.08(.06-.09)$ & 16.36
\end{tabular}

Note: NPI, Narcissistic Personality Inventory; NPI-16, NPI 16 items short version; NPI-13, NPI 13 items short version; S-B⿰⿱乛㇒一大 Satorra-Bentler chi-square; df, degrees of freedom; IFI, incremental fit index; CFI, comparative fit index; RMSEA ( $90 \% \mathrm{Cl})$, root mean square error of approximation ( $90 \%$ confidence interval); AIC, Akaike Information Criterion; ML, maximum likelihood; Criteria for a good fit: $\mathrm{S}-\mathrm{BX} 2 / \mathrm{df} \leq 2, \mathrm{IFI} \geq .95, \mathrm{CFI} \geq .95, \mathrm{RMSEA} \leq .06$, lowest $\mathrm{AIC}$. 
Table 2. Item loadings for the confirmatory 3-factor inter-correlated robust structure of the NPI-13.

$\mathrm{NPI} 13$ items Factor 1: LA Factor 2: GE Factor 3: EE

1. I like having authority over other people.

2. I have a strong will to power.

3. People always seem to recognize my authority.

4. I am a born leader.

5. I know that I am a good person because everybody keeps telling me so.

6. I like to show off my body.

7. I like to look at my body.

8. I will usually show off if I get the chance.

9. I like to look at myself in the mirror.

10. I find it easy to manipulate people.

11. I insist upon getting the respect that is due me.

12. I expect a great deal from other people.

13. I will never be satisfied until I get all that I deserve.

$\begin{array}{lll}.70 & - & - \\ .77 & - & - \\ .74 & - & - \\ .54 & - & - \\ - & .39 & - \\ - & .72 & - \\ - & .64 & - \\ - & .79 & - \\ - & .41 & - \\ - & - & .56 \\ - & - & .42 \\ - & - & .59 \\ - & - & .58\end{array}$

Note: NPI-13, Narcissistic Personality Inventory 13 items short version; NPI-13 LA, Leadership/Authority dimension; NPI-13 $\mathrm{GE}$, Grandiose Exhibitionism dimension; NPI-13 EE, Entitlement/Exploitativeness dimension.

model (Calhoun et al., 2000), three-factor model (Washburn et al., 2004), one-factor short model (Ames et al., 2006), and one- and three-factor short model (Gentile et al., 2013). None of the proposed models fit the NPI and NPI-16 data well. The NPI-13 one-factor model showed a reasonable fit and the NPI-13 three-factor model demonstrated the best fit, obtaining the lowest AIC.

Table 2 displays the item loadings for the three-factor structure of the NPI-13 estimated with the ML Robust method. All items had loadings well above .30 and, thus, none were removed from the model.

Table 3 presents the Pearson correlations between the NPI-13 total and its dimensions. All correlations were significant and positive, with moderately high magnitude.

Table 4 displays the K-R coefficients, the mean inter-item correlations, and the corrected item-total correlation range for the NPI-13 and its dimensions. With the exception of the EE subscale, which had a low K-R value, the NPI-13 demonstrated good internal consistency.

Table 3. Pearson correlation matrix for the NPI-13.

\begin{tabular}{lcccc}
\hline & NPI-13 total & NPI-13 LA & NPI-13 GE & NPI-13 EE \\
\hline $\mathrm{NPI}-13$ total & 1 & & & \\
$\mathrm{NPI}-13 \mathrm{LA}$ & $.84^{* * *}$ & 1 & 1 & \\
$\mathrm{NPI}-13 \mathrm{GE}$ & $.81^{* * *}$ & $.46^{* * *}$ & $.48^{* * *}$ & 1 \\
$\mathrm{NPI}-13 \mathrm{EE}$ & $.83^{* * *}$ & $.62^{* * *}$ &
\end{tabular}

Note: NPI-13, Narcissistic Personality Inventory 13 items short version; NPI-13 LA, Leadership/Authority dimension; NPI-13

$\mathrm{GE}=$ Grandiose Exhibitionism dimension; NPI-13 EE, Entitlement/Exploitativeness dimension.

***Significant at the .001 level.

Table 4. Kuder-Richardson coefficient, mean inter-item correlations, and corrected item-total correlation range for the NPI-13.

\begin{tabular}{lrrrr}
\hline & SR & K-R & MIIC & CITCR \\
\hline NPI-13 total & 13 & .84 & .29 & $.37-.61$ \\
NPI-13 LA & 4 & .77 & .46 & $.45-.71$ \\
NPI-13 GE & 5 & .72 & .34 & $.31-.60$ \\
NPI-13 EE & 4 & .62 & .29 & $.33-.50$ \\
\hline
\end{tabular}

Note: NPI-13, Narcissistic Personality Inventory short version; SR, score range; K-R, Kuder-Richarson coefficient; MIIC, mean inter-item correlation; CITCR, corrected item-total correlation range; NPI-13 LA, Leadership/Authority dimension; NPI-13 $\mathrm{GE}$, Grandiose Exhibitionism dimension; NPI-13 EE, Entitlement/Exploitativeness dimension. 
Table 5. Correlations of the NPI-13 with other measures.

\begin{tabular}{lcccc}
\hline & NPI-13 total & NPI-13 LA & NPI-13 GE & NPI-13 EE \\
\hline APSD-SR total & $.40^{* * *}$ & $.33^{* * *}$ & $.27^{* * *}$ & $.42^{* * *}$ \\
APSD-SR impulsivity & $.35^{* * *}$ & $.27^{* * *}$ & $.26^{* * *}$ & $.33^{* * *}$ \\
APSD-SR Narcissism & $.46^{* * *}$ & $.39^{* * *}$ & $.33^{* * *}$ & $.45^{* * *}$ \\
APSD-SR CU & $-.02^{\mathrm{ns}}$ & $.01^{\mathrm{ns}}$ & $-.08^{\mathrm{ns}}$ & $.04^{\mathrm{ns}}$ \\
YPI total & $.61^{* * *}$ & $.50^{* * *}$ & $.46^{* * *}$ & $.57^{* * *}$ \\
YPI GM & $.60^{* * *}$ & $.49^{* * *}$ & $.49^{* * *}$ & $.52^{* * *}$ \\
YPI CU & $.44^{* * *}$ & $.38^{* * *}$ & $.31^{* * *}$ & $.41^{* * *}$ \\
YPI II & $.44^{* * *}$ & $.35^{* * *}$ & $.29^{* * *}$ & $.46^{* * *}$ \\
CATS & $.16^{*}$ & $.07^{\text {ns }}$ & $.11^{\mathrm{ns}}$ & $.24^{* * *}$ \\
RPQ total & $.42^{* * *}$ & $.37^{* * *}$ & $.25^{* * *}$ & $.44^{* * *}$ \\
RPQ Reactive & $.37^{* * *}$ & $.33^{* * *}$ & $.22^{* * *}$ & $.37^{* * *}$ \\
RPQ Proactive & $.40^{* * *}$ & $.35^{* * *}$ & $.24^{* * *}$ & $.43^{* * *}$ \\
SAS-A total & $.16^{* *}$ & $.07^{\text {ns }}$ & $.19^{* *}$ & $.14^{\text {ns }}$ \\
SAS-A General & $-.02^{\mathrm{ns}}$ & $.02^{\mathrm{ns}}$ & $-.02^{\mathrm{ns}}$ & $-.05^{\mathrm{ns}}$ \\
SAS-A New & $.09^{\mathrm{ns}}$ & $-.01^{\mathrm{ns}}$ & $.12^{\mathrm{ns}}$ & $.11^{\mathrm{ns}}$ \\
SAS-A FNE & $.22^{* *}$ & $.12^{\mathrm{ns}}$ & $.24^{* *}$ & $.17^{*}$ \\
\hline
\end{tabular}

Note: NPI-13, Narcissistic Personality Inventory 13 items short version; NPI-13 LA, Leadership/Authority dimension; NPI-13 GE, Grandiose Exhibitionism dimension; NPI-13 EE, Entitlement/Exploitativeness dimension; APSD-SR, Antisocial Process Screening Device - Self-Report; APSD-SR CU, Callous-Unemotional dimension; YPI, Youth Psychopathic Traits Inventory; YPI GM, Grandiose-Manipulative dimension; YPI CU, Callous-Unemotional dimension; YPI II, Impulsive-Irresponsible dimension; CATS, Child and Adolescent Taxon Scale; RPQ, Reactive-proactive aggression questionnaire; SAS-A, Social Anxiety Scale for Adolescents; SAS-A FNE, Fear of Negative Evaluation dimension.

***Significant at the .001 level.

**Significant at the .01 level.

*Significant at the .05 level; ns= non-significant.

The NPI-13 demonstrated good convergent validity, manifesting moderate to large statistically significant positive correlations with the APSD-SR, YPI, CATS, and RPQ. Discriminant validity was supported by the small, mostly non-significant correlations between the NPI-13 and SAS-A (see Table 5).

Table 6. Correlations of the NPI-13 with other variables.

\begin{tabular}{|c|c|c|c|c|}
\hline & NPI-13 total & NPI-13 LA & NPI-13 GE & NPI-13 EE \\
\hline Age & $.07^{n s}$ & $.08^{\mathrm{ns}}$ & $.04^{\mathrm{ns}}$ & $.03^{\mathrm{ns}}$ \\
\hline Years of education & $.06^{\mathrm{ns}}$ & $.08^{\text {ns }}$ & $.01^{\text {ns }}$ & $.05^{\mathrm{ns}}$ \\
\hline Ethnicity & $-.07^{\mathrm{ns}}$ & $-.03^{\mathrm{ns}}$ & $-.05^{\mathrm{ns}}$ & $-.09^{\text {ns }}$ \\
\hline Psychiatric drugs & $.09^{\mathrm{ns}}$ & $.05^{\mathrm{ns}}$ & $.10^{\mathrm{ns}}$ & $.07^{\mathrm{ns}}$ \\
\hline ACO & $-.16^{*}$ & $-.13^{*}$ & $-.09^{\mathrm{ns}}$ & $-.18^{* *}$ \\
\hline AFPL & $-.09^{\mathrm{ns}}$ & $-.06^{\mathrm{ns}}$ & $-.06^{\mathrm{ns}}$ & $-.11^{\mathrm{ns}}$ \\
\hline AFIJDC & $-.03^{\mathrm{ns}}$ & $.02^{\mathrm{ns}}$ & $-.04^{\mathrm{ns}}$ & $-.06^{\mathrm{ns}}$ \\
\hline CD symptoms & $.46^{* * *}$ & $.36^{* * *}$ & $.32^{* * *}$ & $.48^{* * *}$ \\
\hline$C D$ diagnosis & $.14^{*}$ & $.06^{\mathrm{ns}}$ & $.09^{\mathrm{ns}}$ & $.21^{* *}$ \\
\hline ICS & $.14^{*}$ & $.11^{\mathrm{ns}}$ & $.06^{\mathrm{ns}}$ & $.19^{* *}$ \\
\hline PVC & $.11^{\mathrm{ns}}$ & $.09^{\mathrm{ns}}$ & $.12^{\mathrm{ns}}$ & $.18^{* *}$ \\
\hline NCC & $.05^{\mathrm{ns}}$ & $.14^{*}$ & $-.02^{\mathrm{ns}}$ & $-.01^{\mathrm{ns}}$ \\
\hline Alcohol & $.09^{\mathrm{ns}}$ & $.05^{\mathrm{ns}}$ & $.05^{\mathrm{ns}}$ & $.14^{*}$ \\
\hline Cannabis & $.19^{* *}$ & $.14^{*}$ & $.11^{\mathrm{ns}}$ & $.23^{* * *}$ \\
\hline Cocaine/heroin & $.10^{\mathrm{ns}}$ & $.07^{\mathrm{ns}}$ & $.08^{\mathrm{ns}}$ & $.11^{\mathrm{ns}}$ \\
\hline Unprotected sex & $.09^{\text {ns }}$ & $.10^{\mathrm{ns}}$ & $.03^{\mathrm{ns}}$ & $.10^{\mathrm{ns}}$ \\
\hline
\end{tabular}

Note: NPI-13, Narcissistic Personality Inventory 13 items short version; NPI-13 LA, Leadership/Authority dimension; NPI-13

GE, Grandiose Exhibitionism dimension; NPI-13 EE, Entitlement/Exploitativeness dimension; ACO, Age of crime onset; AFPL, Age of first problem with the law; AFIJDC, Age of first incarceration into a Juvenile Detention Center; CD symptoms, DSM-5 Conduct Disorder symptoms scored as a scale; CD diagnosis, DSM-5 Conduct Disorder diagnosis; ICS, Index of Crime Seriousness; PVC, previous violent crimes; NCC, number of criminal charges.

***Significant at the .001 level.

**Significant at the .01 level.

*Significant at the .05 level; ns= non-significant. 
Correlations with other variables (e.g. age, years of education) were also analyzed. Significant correlations were found between the NPI-13 total and age of crime onset, CD symptoms (scored as a scale), CD diagnosis, crime seriousness, and cannabis use. The $\mathrm{EE}$ dimension also revealed significant correlations with number of previous violent crimes and alcohol use, while the LA dimension revealed a significant correlation with the number of criminal charges (see Table 6). Regarding the DSM-5 Conduct Disorder diagnostic, a very high prevalence rate of $94.1 \%$ was found in our sample.

\section{Discussion}

The purpose of the present study was to assess the psychometric properties of the NPI and its short versions, the NPI-13 and the NPI-16, among a sample of incarcerated male juvenile delinquents. None of the proposed factor models for the NPI and NPI-16 fit the data well. We did however find support for the NPI-13 one- and three-factor models. The latter factor structure demonstrated the best fit, with correlations between the NPI-13 total and its dimensions showing mostly the expected moderate to high statistically significant positive associations. All subsequent psychometric analyses were conducted using this factor structure.

The internal consistency of the NPI-13 was generally good, with values exceeding the recommended minimum level of .70 (Cortina, 1993; Kaplan \& Saccuzzo, 2013), indeed better than the values obtained by Gentile et al. (2013) with young adults and adults. The exception was the EE dimension, which had a lower value of .62. The lower internal consistency of this subscale has been previously noted in research with both the original NPI when using the three-factor structure (Ackerman et al., 2011) and the NPI-13 (Gentile et al., 2013). In the previous research, as in this study, however, this limitation does not seem to impact the overall validity of the dimension. With regard to the mean interitem correlations, the NPI-13 total score and all three subscales demonstrated values within the recommended value range of .15-.50 (Clark \& Watson, 1995), suggesting the items are sufficiently homogeneous. In terms of the corrected item-total correlation range, the NPI-13 total and its three dimensions were all above the recommended value of .20 (Kaplan \& Saccuzzo, 2013; Nunnally \& Bernstein, 1994).

The total NPI-13 and all three domain scores likewise demonstrated good convergent validity with the APSD-SR, YPI, CATS, and RPQ. In general, moderate statistically significant positive correlations were found with each of these measures. As expected, the Narcissism dimension of the APSD-SR and the Grandiose-Manipulative dimension of the YPI manifested the strongest correlations with the NPI-13 and its dimensions suggesting good convergent validity. The main exception was the CU dimension of the APSD-SR, which manifested low non-significant correlations. With regard to discriminant validity, the associations of the NPI-13 (and its dimensions) with the SAS-A (and its dimensions) revealed mostly the expected low non-significant correlations (American Educational Research Association, American Psychological Association, \& National Council for Measurement in Education, 2014; Kaplan \& Saccuzzo, 2013). One notable exception was the FNE dimension of the SAS-A, which obtained mostly positive significant correlations, but some authors (e.g. Hill \& Lapsley, 2011) have previously pointed out that narcissism can be characterized by a maladaptive hypersensitivity to others and increased anxiety in social situations. 
Correlations between the NPI-13 and its dimensions with age, years of education, ethnicity, and psychiatric drug use revealed low, non-significant associations, while correlations with the age of crime onset revealed mostly statistically significant negative associations, although somewhat low in magnitude (the exception being the GE dimension). This is consistent with previous research (e.g. Forth, Kosson, \& Hare, 2003) showing negative associations between dimensions of psychopathy-related traits, such as narcissism, and the age of crime onset variable. No statistically significant correlations were found with age of first problem with the law and age of first incarceration in a Juvenile Detention Center.

The criterion-related validity of the NPI-13 and its dimensions with DSM's (American Psychiatric Association, 2013) Conduct Disorder symptoms revealed moderate associations. However, the point-biserial associations with DSM's (American Psychiatric Association, 2013) Conduct Disorder diagnosis were much lower and statistically significant only for the NPI-13 total and the NPI-13 EE dimension. This may be due to the statistical dichotomization necessary to create the diagnosis variable, as this has been shown to reduce the size of correlations (Marôco, 2014). The high prevalence of conduct disorder found in the current sample (94.1\%) was somewhat higher than those typically found among forensic samples (Sevecke \& Kosson, 2010).

Mostly non-significant statistical correlations emerged between the NPI and measures of criminal behavior such as crime seriousness, previous violent crime, and number of criminal charges. The exceptions were the EE dimension, which was significantly correlated with the first two of these variables (i.e. crime seriousness and previous violent crime), and the LA dimension, which was significantly correlated with the number of criminal charges variable. Because narcissism is considered a facet of the psychopathy construct (Feilhauer \& Cima, 2013), we expected to find more positive statistically significant associations between the NPI-13 and measures of externalizing behavior, similar to those identified in prior studies (e.g. Dolan \& Rennie, 2006; Poythress, Dembo, Wareham, \& Greenbaum, 2006). The correlations of the NPI-13 and its dimensions with alcohol abuse, cocaine/heroin use and unprotected sex revealed mostly low non-significant correlations, with the exception of the low, but significant, positive association between EE dimension and alcohol abuse. This is consistent with previous research showing low non-significant correlations with such externalizing behaviors (e.g. Miller et al., 2010). Cannabis use, on the other hand, revealed mostly positive moderate low statistically significant correlations, and it is worth mentioning that the EE dimension again manifested the highest correlation with cannabis use. We must conclude that our results are consistent with previous research showing that the EE dimension of the NPI13 is the most closely associated with maladaptive variables and outcomes (Ackerman et al., 2011; Gentile et al., 2013).

Our study provides preliminary support for the use of the NPI-13 as short multidimensional measure of narcissism with incarcerated juvenile offenders and also provides some additional support for its use across different cultures/ethnic groups. Specifically, we were able to demonstrate that the NPI-13 demonstrates good psychometric properties with a Portuguese youth forensic population, justifying its future use with similar samples. Our findings corroborate the notion that narcissism in adolescents is best conceptualized as a multidimensional construct, a finding that is in line with the existing adult literature (see Morf \& Rhodewalt, 2001). It is important to mention that the three narcissism 
dimensions showed different associations and that the EE dimension may be particularly useful in understanding juvenile delinquency which is consistent with prior research (Barry et al., 2007).

The narcissism construct may provide an important contribution to the understanding of youth psychological development and its relation to juvenile delinquency and antisocial behaviors. Assessing narcissistic traits in young adolescents may assist juvenile justice workers in an earlier and more accurate identification of youth at-risk for externalizing problems and antisocial behaviors. It may help to identify developmental pathways and assist in identifying young adolescents who could benefit from early preventive interventions, facilitating also the prevention of future adult personality disorders and its understanding (Washburn et al., 2004). The NPI-13 measure of narcissism may be used as a research tool to further investigate the relationship between narcissism and juvenile delinquency, but it may also help to delineate narcissism construct and its potential application to a wider range of adolescent populations and issues. For example, it may be informative to examine possible differences between offender and the non-offender samples, between low-level offenders and serious/violent offenders, and between clinical samples and other types of samples (e.g. forensic, community).

The current findings should be considered in light of several limitations however, such as the small sample size because CFA generally demands a larger sample size. In addition, most measures used in the current study were based on self-report, so future research should seek to utilize multiple methods as well as multiple informants across different samples. The current study was cross-sectional, and, therefore, we recommend that future research use longitudinal designs to examine the contribution of narcissistic traits to antisocial behavior. Along these lines, future research will need to analyze additional metrics (e.g. temporal stability, structural invariance). Lastly, the generalizability of our findings may be limited in terms of external validity. Thus, the psychometric properties of the NPI and its variations should be evaluated among more diverse samples (e.g. females, ethnic minorities). Despite these limitations, the NPI-13 appears to be a promising brief measure of grandiose narcissism among male juvenile offenders. Considering the enormous costs that juvenile offenders create in terms of their crimes and collateral effects on victims and society as a whole, we hope that our study may promote future research on the narcissism construct among this population and a more generalized use of the NPI-13.

\section{Funding}

This study was conducted at Psychology Research Centre, University of Minho, supported by the Portuguese Foundation for Science and Technology (FCT) [Grant SFRH/BPD/86666/2012] with co-financing of the European Social Fund (POPH/FSE), the Portuguese Ministry of Education and Science (MEC), the FEDER under the PT2020 Partnership Agreement (UID/PSI/01662/2013), and national funds provided by FCT- Foundation for Science and Technology [UID/SOC/04020/2013].

\section{References}

Ackerman, R., Witt, E., Donnellan, M., Trzesniewski, K., Robins, R., \& Kashy, D. (2011). What does the narcissistic personality inventory really measure? Assessment, 18, 67-87. 
American Educational Research Association, American Psychological Association, \& National Council for Measurement in Education. (2014). Standards for educational and psychological testing. Washington, DC: AERA.

American Psychiatric Association. (2013). Diagnostic and statistical manual of mental disorders (5th ed.). Washington, DC: Author.

Ames, D., Cameron, P., \& Anderson, P. (2006). The NPI-16 as a short measure of narcissism. Journal of Research in Personality, 40, 440-450.

Ames, D. R., Rose, P., \& Anderson, C. P. (2006). The NPI-16 as a short measure of narcissism. Journal of Research of Personality, 40, 440-450.

Andershed, H., Gustafson, S. B., Kerr, M., \& Stattin, H. (2002). The usefulness of self-reported psychopathy-like traits in the study of antisocial behaviour among non-referred adolescents. European Journal of Personality, 16(5), 383-402.

Andershed, H., Kerr, M., Stattin, H., \& Levander, S. (2002). Psychopathic traits in non-referred youths: Initial test of a new assessment tool. In E. Blaauw \& L. Sheridan (Eds.), Psychopaths: Current international perspectives (pp. 131-158). Haag: Elsevier.

Ang, R. P., \& Yusof, N. (2005). The relationship between aggression, narcissism, and self-esteem in Asian children and adolescents. Current Psychology, 24(2), 113-122.

Barry, C. T., Frick, P. J., \& Killian, A. L. (2003). The relation of narcissism and self-esteem to conduct problems in children: A preliminary investigation. Journal of Clinical Child and Adolescent Psychology, 32(1), 139-152.

Barry, C. T., Grafeman, S. J., Adler, K. K., \& Pickard, J. D. (2007). The relations among narcissism, selfesteem, and delinquency in a sample of at-risk adolescents. Journal of Adolescence, 30(6), 933-942.

Barry, C. T., \& Kauten, R. L. (2014). Non-pathological and pathological narcissism: Which self-reported characteristics are most problematic in adolescents? Journal of Personality Assessment, 96, 212219.

Barry, C. T., Kerig, P. K., Stellwagen, K. K., \& Barry, T. D. (2011). Narcissism and Machiavellianism in youth: Implications for the development of adaptive and maladaptive behavior. Washington, DC: American Psychological Association.

Barry, C. T., Pickard, J. D., \& Ansel, L. L. (2009). The associations of adolescent invulnerability and narcissism with problem behaviors. Personality and Individual Differences, 47(6), 577-582.

Baumeister, R. F., Smart, L., \& Boden, J. M. (1996). Relation of threatened egotism to violence and aggression: The dark side of high self-esteem. Psychological Review, 103(1), 5-33.

Bentler, P., \& Wu, E. (2008). EQS for windows user's guide. Encino, CA: Multivariate Software.

Bushman, B. J., \& Baumeister, R. F. (1998). Threatened egotism, narcissism, self-esteem, and direct and displaced aggression: Does self-love or self-hate lead to violence? Journal of Personality and Social Psychology, 75(1), 219-229.

Byrne, B. (2006). Structural equation modeling with EQS: Basic concepts, applications, and programming. Mahwah, NJ: Lawrence Erlbaum Associates.

Calhoun, G., Glaser, B., Stefurak, T., \& Bradshaw, C. (2000). Preliminary validation of the narcissistic personality inventory-juvenile offender. International Journal of Offender Therapy and Comparative Criminology, 44(5), 564-580.

Campbell, W. K., Bush, C. P., Brunell, A. B., \& Shelton, J. (2005). Understanding the social costs of narcissism: The case of tragedy of the commons. Personality and Social Psychology Bulletin, 31, 13581368.

Campbell, W. K., \& Foster, J. D. (2007). The narcissistic self: Background, an extended agency model, and ongoing controversies. In C. Sedikides \& S. Spencer (Eds.), Frontiers in social psychology: The self (pp. 115-138). Philadelphia, PA: Psychology Press.

Campbell, W. K., Foster, C. A., \& Finkel, E. J. (2002). Does self-love lead to love for others? A story of narcissistic game playing. Journal of Personality and Social Psychology, 83, 340-354.

Caputo, A., Frick, P., \& Brodsky, S. (1999). Family violence and juvenile sex offending. Criminal Justice and Behavior, 26, 338-356.

Chabrol, H., Van Leeuwen, N., Rodgers, R., \& Séjourné, N. (2009). Contributions of psychopathic, narcissistic, Machiavellian, and sadistic personality traits to juvenile delinquency. Personality and Individual Differences, 47(7), 734-739. 
Clark, L., \& Watson, D. (1995). Constructing validity: Basic issues in objective scale development. Psychological Assessment, 7(3), 309-319.

Cooke, D., \& Michie, C. (2001). Refining the construct of psychopathy: Towards a hierarchical model. Psychological Assessment, 13, 171-188.

Corry, N., Merritt, R., Mrug, S., \& Pamp, B. (2008). The factor structure of the narcissistic personality inventory. Journal of Personality Assessment, 90, 593-600.

Cortina, J. (1993). What is coefficient alpha? An examination of theory and applications. Journal of Applied Psychology, 78(1), 98-104.

Dolan, M., \& Rennie, C. (2006). Psychopathy checklist: Youth version and youth psychopathic trait inventory: A comparison study. Personality and Individual Differences, 41(4), 779-789.

Emmons, R. A. (1984). Factor analysis and construct validity of the narcissistic personality inventory. Journal of Personality Assessment, 48, 291-300.

Emmons, R. A. (1987). Narcissism: Theory and measurement. Journal of Personality and Social Psychology, 52, 11-17.

Feilhauer, J., \& Cima, M. (2013). Youth psychopathy: Differential correlates of callous-unemotional traits, narcissism, and impulsivity. Forensic Science International, 224(1-3), 1-7.

Feilhauer, J., Cima, M., \& Arntz, A. (2012). Assessing callous-unemotional traits across different groups of youths: Further cross-cultural validation of the Inventory of Callous-Unemotional Traits. International Journal of Law and Psychiatry, 35(4), 251-262.

Forth, A., Kosson, D., \& Hare, R. (2003). Hare psychopathy checklist: Youth version (PCL:YV): Technical manual. Toronto, ON: Multi-Health Systems.

Foster, J. D., \& Campbell, W. K. (2007). Are there such things as "Narcissists" in social psychology? A taxometric analysis of the narcissistic personality inventory. Personality and Individual Differences, $43,1321-1332$.

Foster, J. D., Campbell, W. K., \& Twenge, J. M. (2003). Individual differences in narcissism: Inflated selfviews across the lifespan and around the world. Journal of Research in Personality, 37, 469-486.

Foster, J. D., \& Trimm, R. F. (2008). On being eager and uninhibited: Narcissism and approach-avoidance motivation. Personality and Social Psychology Bulletin, 34, 1004-1017.

Frick, P., \& Hare, R. (2001). The antisocial process screening device (APSD): Technical manual. Toronto, ON: Multi-Health Systems.

Gentile, B., Miller, J., Hoffman, B., Reidy, D., Zeichner, A., \& Campbell, W. (2013). A test of two brief measures of grandiose narcissism: The narcissistic personality inventory-13 and the narcissistic personality inventory-16. Psychological Assessment, 25(4), 1120-1136.

Hambleton, R., Merenda, P., \& Spielberger, C. (2005). Adapting educational and psychological tests for cross-cultural assessment. Mahwah, NJ: Lawrence Erlbaum Associates.

Hare, R. (2003). Hare psychopathy checklist-revised (2nd ed.). Toronto: Multi-Health Systems.

Harris, G., Rice, M., \& Quinsey, V. (1994). Psychopathy as a taxon: Evidence that psychopaths are a discrete class. Journal of Consulting and Clinical Psychology, 62, 387-397.

Hill, P., \& Lapsley, D. (2011). Adaptive and maladaptive narcissism in adolescent development. In C. T. Barry, P. Kerig, K. Stellwagen, \& T. D. Barry (Eds.), Implications of narcissism and machiavellianism for the development of prosocial and antisocial behavior in youth (pp. 89-105). Washington, DC: APA Press.

IBM SPSS. (2013). IBM SPSS statistics base 22. Chicago, IL: SPSS.

Kaplan, R., \& Saccuzzo, D. (2013). Psychological testing: Principles, applications, and issues (8th ed.). Belmont, CA: Wadsworth, Cengage Learning.

Kauten, R., Barry, C. T., \& Leachman, L. (2013). Do perceived social stress and resilience influence the effects of psychopathy-linked narcissism and CU traits on adolescent aggression? Aggressive Behavior, 39, 381-390.

Kubarych, T. S., Deary, I. J., \& Austin, E. J. (2004). The narcissistic personality inventory: Factor structure in a non-clinical sample. Personality and Individual Differences, 36, 857-872.

La Greca, A., \& Lopez, N. (1998). Social anxiety among adolescents: Linkages with peer relations and friendships. Journal of Abnormal Child Psychology, 26(2), 83-94.

Leech, N., Barrett, K., \& Morgan, G. (2015). SPSS for intermediate statistics: Use and interpretation (5th ed.). New York, NY: Routledge. 
Luhtanen, R. K., \& Crocker, J. (2005). Alcohol use in college students: Effects of level of self-esteem, narcissism, and contingencies of self-worth. Psychology of Addictive Behaviors, 19, 99-103.

Lynam, D. R. (2011). Psychopathy and narcissism. In W. K. Campbell \& J. D. Miller (Eds.), The handbook of narcissism and narcissistic personality disorder: Theoretical approaches, empirical findings, and treatments (pp. 272-282). Hoboken, NJ: John Wiley \& Sons.

Marôco, J. (2014). Análise de Equações Estruturais: Fundamentos teóricos, software \& aplicações [Structural equations analysis: Theoretical foundations, software and applications]. Pero Pinheiro: ReportNumber.

Miller, J. D., Dir, A., Gentile, B., Wilson, L., Pryor, L. R., \& Campbell, W. K. (2010). Searching for a vulnerable dark triad: Comparing Factor 2 psychopathy, vulnerable narcissism, and borderline personality disorder. Journal of Personality, 78, 1529-1564.

Miller, J. D., Hoffman, B. J., Gaughan, E. T., Gentile, B., Maples, J., \& Campbell, W. K. (2011). Grandiose and vulnerable narcissism: A nomological network analysis. Journal of Personality, 79, 1013-1042.

Morf, C., \& Rhodewalt, F. (2001). Unraveling the paradoxes of narcissism: A dynamic self-regulatory processing model. Psychological Inquiry, 12(4), 177-196.

Nevicka, B., Ten Velden, F. S., De Hoogh, A. H., \& Van Vianen, A. E. (2011). Reality at odds with perceptions: Narcissistic leaders and group performance. Psychological Science, 22, 1259-1264.

Newman, J. P., MacCoon, D. G., Vaughn, L. J., \& Sadeh, N. (2005). Validating a distinction between primary and secondary psychopathy with measures of Gray's BIS and BAS constructs. Journal of Abnormal Psychology, 114, 319-323.

Nunnally, J., \& Bernstein, I. (1994). Psychometric theory. New York, NY: McGraw-Hill.

Paulhus, D. L., \& Williams, K. M. (2002). The dark triad of personality: Narcissism, Machiavellianism, and psychopathy. Journal of Research in Personality, 36, 556-563.

Pechorro, P., Andershed, H., Ray, J., Maroco, J., \& Gonçalves, R. (2015). Validation of the youth psychopathic traits inventory and youth psychopathic traits inventory - short among incarcerated juvenile delinquents. Journal of Psychopathology and Behavioral Assessment, 37(4), 576-586.

Pechorro, P., Ayala-Nunes, L., Nunes, C., Maroco, J., \& Gonçalves, R. (in press). The social anxiety scale for adolescents: Measurement invariance and psychometric properties among a school sample of Portuguese youths. Child Psychiatry and Human Development. doi: 10.1007/s10578016-0627-6

Pechorro, P., Hidalgo, V., Nunes, C., \& Jiménez, L. (in press). Confirmatory factor analysis of the antisocial process screening device: Self-Report among incarcerated male juvenile offenders. International Journal of Offender Therapy and Comparative Criminology. doi:10.1177/ $0306624 X 15588903$

Pechorro, P., Maroco, J., Poiares, C., \& Vieira, R. (2013). Validation of the Portuguese version of the antisocial process screening device - Self-report (APSD-SR) with a focus on delinquent behavior and behavior problems. International Journal of Offender Therapy and Comparative Criminology, 57(1), 112-126.

Pechorro, P., Ray, J., Raine, A., Maroco, J., \& Gonçalves, R. (in press). The reactive-proactive aggression questionnaire: Validation among a Portuguese sample of incarcerated juvenile delinquents. Journal of Interpersonal Violence. doi:10.1177/0886260515590784

Pechorro, P., Silva, I., Maroco, J., \& Gonçalves, R. (2014). Propriedades psicométricas da Escala de Ansiedade Social para Adolescentes (SAS-A) em jovens institucionalizados [Psychometric properties of the Social Anxiety Scale for Adolescents (SAS-A) among institutionalized youth]. Psicologia, Saúde e Doenças, 15(3), 586-596.

Perez, R., Thoreson, R., Patton, M., \& Heppner, P. (1997). Problem solving appraisal and narcissism among delinquent adolescents. Journal of Offender Rehabilitation, 26, 19-44.

Porter, S., \& Woodworth, M. (2006). Psychopathy and aggression. In C. Patrick (Ed.), Handbook of psychopathy (pp. 481-494). New York, NY: Guilford Press.

Poythress, N., Dembo, R., Wareham, J., \& Greenbaum, P. (2006). Construct validity of the youth psychopathic features inventory (YPI) and the antisocial process screening device (APSD) with justiceinvolved adolescents. Criminal Justice and Behavior, 33(1), 26-55.

Quinsey, V., Harris, V., Rice, M., \& Cormier, C. (2006). Violent offenders: Appraising and managing risk (2nd ed.). Washington, DC: American Psychological Association. 
Raine, A., Dodge, K., Loeber, R., Gatzke-Kopp, L., Lynam, D., Reynolds, C., ... Liu, J. (2006). The reactiveproactive aggression questionnaire: Differential correlates of reactive and proactive aggression in adolescent boys. Aggressive Behavior, 32, 159-171.

Raskin, R., \& Terry, H. (1988). A principal-components analysis of the narcissistic personality inventory and further evidence of its construct validity. Journal of Personality and Social Psychology, 54, 890902.

Raskin, R. N., \& Hall, C. S. (1979). A narcissistic personality inventory. Psychological Reports, 45, 590.

Robins, R. W., \& Trzesniewski, K. H. (2005). Self-esteem development across the lifespan. Current Directions in Psychological Science, 14, 158-162.

Ryan, K. M., Weikel, K., \& Sprechini, G. (2008). Gender differences in narcissism and courtship violence in dating couples. Sex Roles, 58, 802-813.

Sevecke, K., \& Kosson, D. (2010). Relationships of child and adolescent psychopathy to other forms of psychopathology. In R. Salekin \& D. Lynam (Eds.), Handbook of child and adolescent psychopathy (pp. 284-314). New York, NY: Guilford Press.

Stinson, F. F., Dawson, D. A., Goldstein, R. B., Chou, S. P., Smith, S. M., Ruan, W. J. ... Grant, B. F. (2008). Prevalence, correlates, disability and comorbidity of DSM-IV narcissistic personality disorder: Results from the wave 2 national epidemiologic survey on alcohol and related conditions. Journal of Clinical Psychiatry, 69, 1033-1045.

Twenge, J. M., \& Campbell, W. K. (2003). "Isn't it fun to get the respect that we're going to deserve?" Narcissism, social rejection, and aggression. Personality and Social Psychology Bulletin, 29, 261-272.

Washburn, J., McMahon, S., King, C., Reinecke, M., \& Silver, C. (2004). Narcissistic features in young adolescents: Relations to aggression and internalizing symptoms. Journal of Youth and Adolescence, 33(3), 247-260.

Watson, P. J., Grisham, S. O., Trotter, M. V., \& Biderman, M. D. (1984). Narcissism and empathy: Validity evidence for the narcissistic personality inventory. Journal of Personality Assessment, 45, 159-162.

West, S., Taylor, A., \& Wu, W. (2012). Model fit and model selection in structural equation modeling. In R. Hoyle (Ed.), Handbook of structural equation modeling (pp. 209-231). New York, NY: The Guilford Press.

White, J., Moffitt, T., Caspi, A., Jeglum-Bartusch, D., Needles, D., \& Stouthamer-Loeber, M. (1994). Measuring impulsivity and examining its relation to delinquency. Journal of Abnormal Psychology, 103, 192-205.

Wilson, M. S., \& Sibley, C. G. (2011). 'Narcissism creep?': Evidence for age-related differences in narcissism in the New Zealand general population. New Zealand Journal of Psychology, 40(3), 89-95. 